\title{
Study on the functional properties of indigenous probiotics isolated from human samples in West Africa
}

\section{Abstract}

2 A study was performed to identify and characterize 99 indigenous strains isolated from human breast 3 milk $(n=29)$ and fecal samples $(n=70)$ in Ghana, using methods ranging from plating growth tests, 4 conforming to (NCCLS) standards and presumptive analysis at species level using MALDI-TOF MS,

5 prior to validation through $\mathrm{qPCR}$ techniques. Antimicrobial activities of the isolated strains were

6 performed by the agar well diffusion assay. Gastrointestinal tolerance and ability to grow biofilms in $7 \quad$ vitro using 3D Alvatex platform were determined. Results indicate that out of 99 samples, 25 were 8 gram-positive, catalase-negative rods, $80 \%$ of which were Lactobacillus strains. More than one-third 9 of the identified strains were L. fermentum followed by L. plantarum, L. rhamnosus, L. salivarius, L. 10 reuteri along with Enterococcus faecium, Weissella spp. and Pediococcus spp. Among the 25 11 isolates, 9 had activity against both gram-negative and gram-positive tested pathogens including 12 Staphylococcus aureus, Escherichia coli ATCC 25922, E. coli BAA-2471, Salmonella typhi, and

13 Pseudomonas aeruginosa. The indigenous microbiota proved to be most effective antimicrobial to

14 local pathogens over nonindigenous pathogens. The data also showed maintained cell viability for all 15 studied isolate at $\mathrm{pH} \mathrm{2,3}$ and 6 followed by a successful growth of the co-cultured biofilm in a 3D 16 Alvatex platform.

17 Keywords: Microbiome; Probiotics; Lactic Acid Bacteria (LAB); Lactobacillus; indigenous strains 


\section{Introduction}

20 During the $20^{\text {th }}$ century, little was known about the beneficial attributes of some commensal bacteria

21 before the noble laureate Elie Metchninkoff introduces the concept of probiotics and their boosting 22 effects on human health (Metchnikoff, 1908). In view of this original contribution, various studies

23 have then been implemented by microbiome researchers including the World Health Organization

24 (WHO) to ascertain the health benefits from an adequate amount of probiotics to the host. Among

25 commensal microorganisms pertaining to fermented food and dairy industry (i.e., Yogurt, Kefir and

26 cheese), lactic acid bacteria (LAB), primarily species descending from the Lactobacillus genera, have

27 been extensively used for their fermentative ability and probiotic potential (FAO/WHO, 2001;

28 Linares, Ross, \& Stanton, 2016). Within LABs, some Lactobacillus strains constitute the most

29 prevalent components of the gastrointestinal tract (gut) and vaginal microbiota (Metchnikoff, 1908;

30 Westerik, Kort, Sybesma, \& Reid, 2018). These strains can form biofilms in the host cells and protect

31 them from infective bacteria such as mastitis pathogens, by producing bacteriocins, which act as

32 antimicrobials, in addition to hydrogen peroxide and lactic acid (Ocana \& Nader-Macias, 2004). The

33 most common species of Lactobacillus strains used in food have been extensively documented

34 (Salas-Jara, Ilabaca, Vega, \& Garcia, 2016; Tamang, Watanabe, \& Holzapfel, 2016). Furthermore, L.

35 rhamnosus GG ATCC 53103 (Valio) along with L. rhamnosus GR-1 as well as L. paracasei Shirota

36 (Yakult) and B. lactis BB12 (Chr. Hansen) are the world's most documented probiotics, which also

37 dominate the probiotic market. These species originating from America, Asia and Europe have

38 shown high efficacy in the management of lactose intolerance, immune response modulation, and

39 protection against Clostridium difficile and Helicobacter pylori infections. According to Linares et al.

40 (2016) and Westerik et al. (2018), they also protect bacteria and fungi in the urogenital, gut, and

41 respiratory tract, as well as against rotaviral and antibiotic-associated infections along with Travelers'

42 diarrhea. 
43 While controlled trials have shown that some strains are able to reduce the symptoms of irritable

44 bowel syndrome (IBS) and inflammation in ulcerative colitis (Guslandi, 2007) and the rate of 45 rotavirus-associated diarrhea (Dubey, Rajeshwari, Chakravarty, \& Famularo, 2008), other studies 46 suggest that these probiotics have potential to increase cure rate for bacterial vaginosis (Martinez et 47 al., 2009) and decrease incidence of allergic diseases (Abrahamsson et al., 2007) as well as, 48 postoperative complications of colorectal cancer (Zhang et al., 2012). They also have been shown to 49 improve quality of life in children with cystic fibrosis (Jafari et al., 2013). Furthermore, recent research has suggested in addition to the functional properties of the human microbiota, the latter also

51 plays a role in brain development and can be linked to autism, depression, anxiety and stress 52 (Abildgaard, Elfving, Hokland, Wegener, \& Lund, 2017; Kraus, Cetin, \& Aricioglu, 2016; Nduti et 53 al., 2016; Sawada et al., 2017; Severance et al., 2017).

54 Although these species have been extensively applied in Africa (Bisanz et al., 2014; Nduti et al., 55 2016), there is an unmet need to isolate indigenous strains, which have adapted to local conditions 56 and have potential to be more specific to the local population. Various probiotics and their potential 57 benefits have been identified and reported, however, there is limited information on isolated and 58 documented indigenous probiotic microorganisms. While there is a research study on potential 59 probiotic isolates from fermented food in Ghana (Owusu-Kwarteng, Tano-Debrah, Akabanda, \& 60 Jespersen, 2015), little is known about their benefits to the residents. We believe that the indigenous 61 flora has a high potential to be valuable in the management of enteric infections, boost immunity, and 62 generally improve the wellbeing of local population that are often exposed to poor hygiene condition, 63 malnutrition, and chronic enteric infections. Moreover, with our understanding of how an 64 individual's genetics, environment, and diet influence their microbiota and the current trend towards 65 personalized medicine (Vogenberg, Isaacson Barash, \& Pursel, 2010), it has become very important 66 to identify local strains, those which predominate in the specific population. This avoids the one-size- 
67 fits-all approach and generalization of the effectiveness of probiotic species, which often results in

68 lack of efficacy (Allen et al., 2013; Ritchie \& Romanuk, 2012). Locally sourced probiotics are of

69 prime interest pertaining to their immediate availability in the local market and high antimicrobial

70 specificity to residents' host cells.

71 The objective of this study is to identify and characterize the functional properties of locally isolated

72 probiotics from human feces and breast milk samples in Ghana to ascertain the beneficial effects of

73 indigenous probiotics over the non-indigenous strains. Particular focus of this study is to elucidate

74 the prevalence of the most significant probiotics including Lactobacillus strains and determine their

75 antimicrobial activities, biofilm growth ability and resistance to acidic environment. The standards

76 and presumptive identifications were performed using MALDI- TOF MS followed by qPCR

77 techniques. While the antimicrobial activity was tested by the agar well diffusion assay, the in vitro

78 growth of biofilm and the gastrointestinal tolerance were demonstrated using 3D Alvatex platform.

\section{Materials and methods}

\subsection{Isolation and phenotypic identification of LAB species}

81 Fecal samples were obtained from five adults, one adolescent, three children, and three infants. Milk

82 was obtained from six breastfeeding mothers. $1 \mathrm{~g}$ of fecal sample was homogenized in $10 \mathrm{~mL}$ of

83 phosphate buffered saline (PBS, pH 7.4) using a vortex. A loopful of the fecal suspension and breast

84 milk sample was streaked onto separate de Man Rogosa Sharpe (MRS) broth (Oxoid) supplemented 85 with $0.05 \% \mathrm{w} / \mathrm{v}$ L-cysteine hydrochloride and $0.002 \% \mathrm{w} / \mathrm{v}$ of bromophenol blue, and incubated 86 anaerobically at $37^{\circ} \mathrm{C}$ for $48 \mathrm{~h}$. Colonies with different morphological characteristics were picked

87 from the agar plates and cultured on MRS agar supplemented with only $0.05 \%$ L-cysteine

88 hydrochloride (MRSc). The plates were incubated at $37^{\circ} \mathrm{C}$ for $48 \mathrm{~h}$ anaerobically. Pure colonies

89 obtained were Gram-stained and observed under the microscope. Biochemical profile such as the 
catalase test was performed on the isolates. Out of 99 colonies isolated including 29 colonies from

91 breast milk samples and 70 from fecal samples, 25 of the isolates were gram-positive rods and $80 \%$

92 of the isolated species were identified by MALDI-TOF MS or 16S rRNA gene sequencing as

93 belonging to Lactobacillus genus.

\subsection{Identification of isolates using MALDI-TOF}

Isolates were identified by Matrix-Assisted Laser Desorption Ionization Time of Flight Mass

Spectrometry (MALDI-TOF MS) using the MALDI Biotyper ${ }^{\circledR}$. Briefly, a single colony of freshly

98 grown isolated bacteria was smeared as a film onto individual spots on MALDI-target plate using 1

$99 \mu \mathrm{L}$ disposable loop and allowed to air dry. The film was overlaid with $1 \mu \mathrm{L}$ of a $98 \%$ formic acid

100 solution to allow on-plate extraction of cellular proteins. After drying, the film was further overlaid

101 with $1 \mu \mathrm{L}$ of a MALDI-TOF MS matrix comprising of $\alpha$-cyano-4-hydroxycinnamic acid (CHCA)

102 in 50\% acetonitrile and $2.5 \%$ trifluoroacetic acid. The sample was further air-dried for 1-2 min and

103 analysed with the Bruker Microflex LT bench top MALDI-TOF mass spectrometer (Bruker

104 Daltonics, Billerica, MA, USA), Bruker FlexControl 3.0 software, and MALDI Biotyper 3.1 software

105 (Bruker Daltonics, Billerica, MA, USA). The reference strain was Escherichia coli ATCC 8739.

106 Mass spectra for each spotted bacterial isolate was acquired with the instrument in a linear positive

107 mode within a 2-20 kDa range, with ion source 1.0 at $20 \mathrm{kV}$, ion source 2.0 at $18.05 \mathrm{kV}$, the lens at

$1086.0 \mathrm{kV}$, and the linear detector at 2,560 V. Mass spectra was analyzed and compared with the

109 MALDI Biotyper 3.1 software database, comprised of 4,970 distinct bacterial species, to determine

110 the most likely microbial genus and species identification. A MALDI Biotyper score, generated as a

111 level of probability by the software, of $\geq 1.7$ was utilized as a threshold for reliable species

112 identification, as recommended for assessment of anaerobic bacteria (Hsu \& Burnham, 2014). The 
113 MALDI-TOF MS has previously been used for bacterial identification and established as an

114 alternative to bacterial identification providing rapid determination (Levesque et al., 2015;

115 McElvania TeKippe \& Burnham, 2014).

\section{$117 \quad 2.3 \quad$ Identification of isolates using Polymerase Chain Reaction (PCR)}

118 The genomic DNA of the isolated bacteria was extracted using the GenElute ${ }^{\mathrm{TM}}$ Bacterial Genomic 119 DNA Kit (Sigma) according to the manufacturer's protocol. The 16S rRNA gene was amplified 120 using the following primers: 8F, 50-AGAGTTTGATCCTGGCTCAG-30, and 1492R, 50-

121 GGTTACCTTGTTACGACTT-30. PCR was performed using the MJ Mini ${ }^{\mathrm{TM}}$ Thermal Cycler (Bio-

$122 \mathrm{Rad})$. The reaction contained in $50 \mu \mathrm{L}$ total volume, $0.5 \mu \mathrm{M}$ of each primer $(0.5 \mu \mathrm{L}$ of each $), 1 \mu \mathrm{L}$ of

123 genomic DNA, $25 \mu \mathrm{L}$ GoTaq ${ }^{\circledR}$ Master mix (Promega; reaction buffer, $400 \mu \mathrm{M}$ dATP, $400 \mu \mathrm{M}$ dGTP, $124400 \mu \mathrm{M}$ dCTP, $400 \mu \mathrm{M}$ dTTP, $3 \mathrm{mM} \mathrm{MgCl}_{2}$ ) and $23 \mu \mathrm{L}$ RNase free water. The PCR was run under 125 an initial activation at $94^{\circ} \mathrm{C}$ for $2 \mathrm{~min}$, followed by 30 cycles of denaturation step cycles at $94^{\circ} \mathrm{C}$ for $12630 \mathrm{~s}$, an annealing step at $55^{\circ} \mathrm{C}$ for $1 \mathrm{~min}$, extension step at $72^{\circ} \mathrm{C}$ for $1 \mathrm{~min}$ and final cycle at $72^{\circ} \mathrm{C}$ for 12710 min. $9 \mu \mathrm{L}$ aliquots of the PCR samples were subjected to electrophoresis in $0.8 \%$ w/v agarose gel 128 (stained with $0.5 \mu \mathrm{g} / \mathrm{mL}$ ethidium bromide), in TAE buffer. The gel was visualized under UV 129 illumination and photographed. The PCR samples were further purified and sequenced.

\section{$131 \quad 2.4 \quad$ Antimicrobial activity of isolates}

132 Antimicrobial activity of the isolated species was tested by the agar well diffusion assay against

133 Staphylococcus aureus ATCC 29213, Escherichia coli ATCC 25922, E. coli BAA-2471 (multi-drug 134 resistant strain), Salmonella typhi (local clinical isolate), Pseudomonas aeruginosa (local clinical 
135 isolate) and P. aeruginosa ATCC 10145. Briefly, 24 h culture of the isolated species in MRSc were

136 centrifuged at $3500 \mathrm{~g}$ at $4^{\circ} \mathrm{C}$. The supernatant was collected and filter sterilized using a $0.2 \mu \mathrm{m}$

137 membrane syringe filter. A lawn of each test-isolated microorganism was made by picking bacterial

138 colonies and spreading on Mannitol Salt agar (Oxoid), MacConkey agar (Oxoid), Cetrimide agar

139 (Oxoid), Bismuth sulphite agar (Oxoid) or Tryptic Soy agar (Sigma-Aldrich). Wells of $9 \mathrm{~mm}$ in

140 diameter were made in the agar and filled with $150 \mu \mathrm{L}$ of the filter-sterilized supernatant. The plates

141 were kept on the bench for $2 \mathrm{~h}$ for diffusion of the supernatant and then incubated at $37^{\circ} \mathrm{C}$. Zones of 142 inhibition were recorded after $48 \mathrm{~h}$ of incubation.

\section{$144 \quad 2.5 \quad$ Gastrointestinal tolerance assay}

145 Simulated gastric and intestinal juice

146 Tolerance of selected isolated species to simulated gastric fluid and bile salt were performed by

147 inoculating $100 \mu \mathrm{L}$ of a culture of each species in $1 \mathrm{~mL}$ solution $\mathrm{pH}$ adjusted $(\mathrm{HCl} / \mathrm{NaOH})$ to $1,2,3$

148 and 6 and $0.3 \% \mathrm{w} / \mathrm{v}$ bile salt (Sigma-Aldrich). The cells were incubated at $37^{\circ} \mathrm{C}$ and sample taken at

$1491 \mathrm{~h}, 2 \mathrm{~h}$ and $3 \mathrm{~h}$, serially diluted in PBS ( $\mathrm{pH}$ 7.4) and spread-plated on MRSc. Samples for bile salt

150 test were further sampled at $4 \mathrm{~h}$. Colonies were counted after incubation at $37^{\circ} \mathrm{C}$ for $48 \mathrm{~h}$.

\section{$152 \quad 2.6$ Biofilm assay}

153 The ability of selected probiotic species to form a successful biofilm growth in vitro was evaluated.

154 The Alvatex strata 3D scaffold inserts (ReproCELL Europe Ltd., Glasgow, United Kingdom) were

155 used for simulating the structural matrix found in the gut and mimicking in vivo biofilm growth of

156 the bacteria. Each species was grown separately in MRSc broth as previously described. The 3D 
157 scaffold inserts were placed carefully into wells of the plate. The scaffolds were washed with $400 \mu \mathrm{L}$

158 of 200-proof ethanol, then $550 \mu \mathrm{L}$ of sterile PBS. $550 \mu \mathrm{L}$ of sterile PBS was again poured carefully

159 into the wells making sure the 3D fibrous scaffolds lay flat without any folding. The 3D fibrous

160 scaffolds were UV sterilized for $45 \mathrm{~min}$. The PBS was removed carefully from the wells and replaced

161 with $550 \mu \mathrm{L}$ of sterile MRSc, which was also carefully removed. $400 \mu \mathrm{L}$ bacterial culture were

162 inoculated into the wells containing the UV sterilized 3D fibrous scaffold and incubated at $37^{\circ} \mathrm{C}$ for 5

163 days with addition of MRSc as necessary. At the end of incubation the biofilms were stained with the

164 FilmTracer ${ }^{\mathrm{TM}}$ LIVE/DEAD $^{\mathrm{TM}}$ (Invitrogen ${ }^{\mathrm{TM}}$ ) Biofilm Viability kit (a two-colour fluorescence assay

165 of bacterial viability: SYTO ${ }^{\circledR} 9$ green fluorescent nucleic acid stain and red-fluorescent nucleic acid

166 stain, propidium iodide) and imaged using EVOS ${ }^{\circledR}$ FL Cell Imaging System at 40X resolution.

\section{Results}

\subsection{Isolation and identification of isolates}

169 Several isolates were obtained from fecal (adults, adolescent, children and infants) and breast milk 170 samples on MRSc media. The isolates were Gram-stained, analyzed by microscopic observation and

171 catalase test. Out of 99 colonies isolated including 29 colonies from breast milk samples and 70 from

172 fecal samples, 25 of the isolates were gram-positive rods and catalase negative. The 25 gram-positive

173 catalase negative rods were submitted to MALDI-TOF MS and 16S rRNA gene sequencing analysis

174 (Table 1). More than $80 \%$ of the isolated species were identified by MALDI-TOF MS or 16S rRNA

175 gene sequencing as belonging to Lactobacillus genus. More than one-third of the species of were

176 identified as L. fermentum by both identification methods. Other species isolated included $L$.

177 plantarum, L. rhamnosus, L. salivarius, L. reuteri, Enterococcus faecium, Weissella spp. and

178 Pediococcus spp. The Jaccard's similarity coefficient between the MALDI-TOF MS and 16S rRNA

179 gene sequencing methods was almost 70\%. Isolate 8 and 9 were identified by both methods as 
180 Weissella and Pediococcus species respectively. However the Weissella species was identified as

181 Weissella confusa with MALDI-TOF MS and Weissella cibaria with 16S rRNA gene sequencing 182 whilst the Pediococcus species was identified as Pediococcus pentosaceus and Pediococcus

183 acidilactici with both methods respectively. Another isolate identified as L. reuteri by MALDI-TOF

184 MS was identified as L. fermentum by $16 \mathrm{~S}$ rRNA gene sequencing whilst a L. plantarum was 185 identified as L. rhamnosus.

\subsection{Antimicrobial activity of isolates}

188 The antimicrobial activities of isolated species were tested against gram-negative $P$. aeruginosa 189 (ATCC 101145 and local clinical isolate), E. coli (ATCC 25922 and BAA-2471 multi-drug resistant),

190 Salmonella typhi (local clinical isolate) and gram-positive S. aureus (ATCC 29213). Only 9 out of 25

191 isolates had activity against both gram-negative and gram-positive tested bacteria, Table 2. Isolates

192 FSD1-D and FSI3-L showed highest activity against both the gram-negative and gram-positive 193 bacteria, followed by FSD4-D, FSC3-L and FSD3-WC. All tested isolate had activity against $P$. 194 aeruginosa and E. coli. Only one isolate, FSD4-I did not show activity against Salmonella typhi.

195 Also 13 isolates (almost 60\%) did not show zone of inhibition towards S. aureus. Isolate FSI3-L had 196 highest activity against $S$. aureus whereas FSD1-D had highest activity against Salmonella typhi. The 197 relative activity of the isolates against $P$. aeruginosa was greater in the local isolate than the 198 reference strain. The zone of inhibition against the multi-drug resistant E. coli strain was 199 correspondingly smaller than in the reference strain.

\subsection{Gastrointestinal tolerance assay}




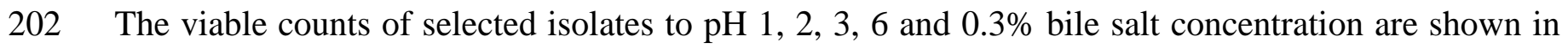

203 Tables 3 and 4. The data shows maintained cell viability for all studied isolate at pH 2, 3 and 6.

204 However, all isolates lost total viability during the acid test at $\mathrm{pH} 1$. The exposure of the isolates to

$2050.3 \%$ bile salt concentration showed general maintenance of viability over the $4 \mathrm{~h}$ exposure period,

206 Table 4.

207

\section{$208 \quad 3.4$ Biofilm assay}

209 The ability of selected isolates to form biofilm was evaluated using the Alvatex 3D scaffold insert

210 (Fig. 1). The confocal imaging (Fig. 1b) of the 3D scaffold at 60x magnification shows randomly

211 aligned fibers associating to form a fibrous mesh. The 3D scaffold was explored to simulate the

212 structural matrix found in the gut and mimic the in vivo biofilm growth of bacteria. All tested species

213 formed biofilm on the 3D scaffold (Fig. 2). The biofilm formed for all species comprised of both live

214 and dead cells. All scaffolds maintained integrity during the period of assay except for scaffold used 215 for culturing isolate FSD1-D.

2174 Discussion

218 In the present investigation, we identified twenty-four potential indigenous probiotic isolates as $L$.

219 fermentum (14), L. plantarum (2), L. rhamnosus (1), L. salivarius (1), L. reuteri (1), Enterococcus 220 faecium (2), Weissella spp. (2) and Pediococcus spp. (1) from breast milk and fecal samples using the

221 MALDI-TOF MS and 16S rRNA gene sequencing analysis. The predominant species in both the

222 breast milk and fecal samples was L. fermentum. Other studies have reported a similar profile for 223 fecal samples (Mandal, Jariwala, \& Bagchi, 2016), more diverse profile for breast milk samples 
224 (Damaceno et al., 2017; Khalkhali \& Mojgani, 2017) or only one type of bacteria from breast milk

225 (Martin et al., 2003). Weisella confusa and Weisella cibaria very closely related species with very

226 high 16S rDNA sequence similarity could not be differentiated by one of the two methods in the

227 present study and previously misidentified (Bjorkroth et al., 2002). Pediococcus pentosaceus and

228 Pediococcus acidilactici are also highly phylogenetically related; 16S rRNA sequence homology of

229 98.3\% (Collins, Williams, \& Wallbanks, 1990; Mora, Fortina, Parini, \& Manachini, 1997) could not

230 be differentiated by one of the methods. Still, isolate FSI1-D was identified as L. reuteri by MALDI-

231 TOF MS and as L. fermentum by $16 \mathrm{~S}$ rRNA gene sequencing analysis (97.75\% identity score). It

232 must be noted that L. fermentum and L. reuteri were previously classified as a single species, because

233 L. fermentum is closely related phenotypically but have subsequently been separated (Klein, Pack,

234 Bonaparte, \& Reuter, 1998). It is interesting that in the present study, one of the two methods could

235 not differentiate the species. The data also showed a Jaccard's similarity coefficient of $84.62 \%$ for the

236 identification of L. fermentum and an overall similarity coefficient of approximately $70 \%$ for the

237 identification of LAB. 16S rRNA gene sequencing analysis is often considered the gold standard for

238 identification of bacteria and it is commonly combined with phenotypic methods/biochemical

239 fermentation strips for identification of LAB, with the latter methods, streamlining the number of

240 species to be identified; however, for routine use in laboratories, 16S rRNA gene sequencing analysis

241 is limited by its time consuming nature and cost. MALDI-TOF MS offers the advantage of a rapid

242 turn-around time and minimal cost and has been previously demonstrated to be highly congruent

$243(86.1 \%)$ to $16 \mathrm{~S}$ rRNA gene sequencing analysis (Garcia et al., 2016). The present data suggests a

244 good congruency between the two methods at the genus level. However it also brings to light the fact

245 that either single identification method may not be sufficient to identify accurately at the species

246 level. 16S rRNA sequencing has been previously suggested to provide more than $90 \%$ genus

247 identification and 65\%-83\% in species identification (Janda \& Abbott, 2007; Mignard \& Flandrois, 248 2006). 
249 It is important that potential probiotic candidates produce extracellular antimicrobial compounds to

250 kill pathogenic bacteria and mitigate infectious diseases. The extracellular antimicrobial compounds

251 may include organic acids, hydrogen peroxide, bacteriocins, low-molecular mass peptides and

252 enzymes. When evaluated for the antimicrobial activity against both gram-negative and gram-

253 positive bacteria, with the exception of FSD4-I, which did not show activity against Salmonella

254 typhi, all the isolates demonstrated inhibitory activity against the tested gram-negative bacteria. The

255 several isolated species of L. fermentum exhibited different inhibitory profile against the tested

256 bacteria suggesting strain specificity of activity also observed by Arena et al. (2016) when studying

257 the antimicrobial activity of several isolated L. plantarum strains against Listeria monocytogenes,

258 Salmonella Enteritidis, E. coli O157:H7 and S. aureus. McCoy and Gilliland (2007) also

259 demonstrated variations of some isolated L. reuteri species in inhibiting growth of Salmonella

260 Typhimurium noting the ability of some $L$. reuteri species to produce reuterin whilst others did not. In

261 the present study, it was noted that the isolates were generally more effective against the local clinical

262 isolate of $P$. aeruginosa than $P$. aeruginosa ATCC 10145. This observation supports that indigenous

263 isolates may be more effective in the treatment of native infections and also more specific to the

264 microbiota of the local population. However the reason for this is not currently known but may be

265 explained to be possibly the previous evolvement and association of the potential probiotic isolates

266 (from the microbiota) with the local P. aeruginosa. The species were also more effective against the

267 gram-negative species than the gram-positive $S$. aureus. However, this greater effectiveness towards

268 gram-negative bacteria was not reported by Mandal et al. (2016) when they assessed isolated LAB

269 against E. coli, P. aeruginosa, Salmonella Typhi, Shigella dysenteriae, Proteus vulagaris and $S$.

270 aureus in a similar study. Tharmaraj and Shah (2009) reported a higher inhibition of gram-positive

271 bacteria including S. aureus than gram-negative bacteria when evaluating the antimicrobial effects of

272 probiotics against selected pathogenic and spoilage bacteria in cheese-based dips (Tharmaraj \& Shah,

273 2009). On the other hand, Tirloni et al. (2014) reported a higher susceptibility of gram-negative 
bacteria to antimicrobial activities of $L$. animalis and L. paracasei although $P$. aeruginosa was one of

275 the least susceptible species (Tirloni et al., 2014).

276 For probiotic species to exert their activity, they must first colonize the gastrointestinal tract. The

277 ability of selected isolates to survive gastrointestinal tolerance was tested in $\mathrm{pH} 1$ to 6 and $0.3 \% \mathrm{w} / \mathrm{v}$

278 bile salt concentration for $3 \mathrm{~h}$ and more. None of the tested isolates survived at $\mathrm{pH} 1$ for the period

279 tested and for $30 \mathrm{~min}$ after inoculation (results not shown). All tested isolates were resistant to $\mathrm{pH} 2$

280 and above and the bile salt. The human stomach has $\mathrm{pH}$ ranging from 1 to 2.5 in the fasted states but

281 can peak to 6.7 in the fed state (Dressman et al., 1990; Evans et al., 1988). Although most of the

282 harsh conditions of the gastric environment is contributed by the $\mathrm{pH}$, other enzymatic and digestive

283 substance contained in the gastric fluid as well as the presence of food and the delivery matrix for the

284 probiotic bacteria could affect the survival of the cells during gastrointestinal transit (Fredua-

285 Agyeman \& Gaisford, 2015). The results indicate that the tested isolates may survive passage

286 through the gastrointestinal at those $\mathrm{pH}$ and bile salt concentration; however, a more biorelevant test

287 may be required. The resistance of the isolates was better than previously reported (Garcia et al.,

288 2016; Jacobsen et al., 1999).

The establishment of the biofilm forming potential of the isolates is very important as the bacterial association within the gut predominantly exist as biofilms. Biofilm provide colonization resistance; they prolong the residence of ingested bacteria, suppress pathogenic microorganisms and interact with the host cells to regulate immunity (de Vos, 2015; Sassone-Corsi \& Raffatellu, 2015). The examined species in the present study all showed biofilm forming potential on 3D nanofibrous scaffold. It was however observed that some of the species were self-inhibitory, having a greater proportion of dead than live cells at the end of incubation period. Although quantification of metabolic products such as organic acids, hydrogen peroxide was not made in the present study, the $\mathrm{pH}$ measurements of supernatants produced by the species suggest organic acids may have played a 
role. The lowest $\mathrm{pH}$ (pH of 3.8) was recorded for FSD1-D, which digested the 3D scaffold (Fig. 3)

299 followed by FSC3-LBC ( $\mathrm{pH} 4.2)$. The digestion of the scaffold however could not be replicated in

$300 \mathrm{HCl}$ at similar $\mathrm{pH}$.

301 Ultimately, the indigenous microbiota proved to be the most effective antimicrobial for residents over

302 the nonindigenous probiotics, in addition to their potential to regulate host serotonin biosynthesis in

303 the gut as was previously documented by Yano et al. (2015). Our research study herein, demonstrated

304 the capability of some indigenous strains of Lactobacillus to effectively inhibit pathogens in the gut

305 and withstand severe in vivo conditions, suggesting their combination with commercialized

306 probiotics in order to optimize the indigenous efficiency.

307 They also have exceptional ability to withstand extreme $\mathrm{pH}$ conditions. Although our preliminary

308 data on the antibiotic resistance profiling of some strains (results not shown) revealed the presence of

309 some probiotics carrying resistance, future research studies and directions will be focused towards

310 further investigation on the antibiotic resistance profiling to ensure the selection of strains that are

311 free from resistance, which will warrant the benefits and safe-use of this natural therapy. Perhaps, the

312 biofilm will also be enhanced towards the fourth-generation encapsulation to ensure greater in vivo

313 bioavailability and potency towards pathogens in the gut.

\section{Acknowledgments}

315 We would like to thank the University of South Florida Provost, Dr. Ralph Wilcox, for his

316 encouragement and support in offering additional expenses for laboratory consumables to facilitate

317 sustained research collaboration. Furthermore, we would like to extend thanks to the Research,

318 Innovation and Global Affairs department of USF.

$3196 \quad$ Funding 
320 This work was supported by the BANGA-Africa Program funded by the Carnegie Corporation of

321 New York. Mansa Fredua-Agyeman is a recipient of the BANGA-Africa Seed Grant and Post-

322 Doctorial Fellowship award.

$323 \quad$ Conflict of Interest

324 The authors declare that the research was conducted in the absence of any commercial or financial

325 relationships that could be construed as a potential conflict of interest.

326 
328 Abildgaard, A., Elfving, B., Hokland, M., Wegener, G., \& Lund, S. (2017). Probiotic treatment

329 reduces depressive-like behaviour in rats independently of diet. Psychoneuroendocrinology 79, $40-$ 33048.

331 Abrahamsson, T. R., Jakobsson, T., Bottcher, M. F., Fredrikson, M., Jenmalm, M. C., Bjorksten, B., 332 et al. (2007). Probiotics in prevention of IgE-associated eczema: a double-blind, randomized,

333 placebo-controlled trial. J Allergy Clin Immunol 119, 1174-1180.

334 Allen, S. J., Wareham, K., Wang, D., Bradley, C., Hutchings, H., Harris, W., et al. (2013).

335 Lactobacilli and bifidobacteria in the prevention of antibiotic-associated diarrhoea and Clostridium

336 difficile diarrhoea in older inpatients (PLACIDE): a randomised, double-blind, placebo-controlled,

337 multicentre trial. Lancet, 382(9900), 1249-1257.

338 Arena, M. P., Silvain, A., Normanno, G., Grieco, F., Drider, D., Spano, G., et al. (2016). Use of

339 Lactobacillus plantarum Strains as a Bio-Control Strategy against Food-Borne Pathogenic

340 Microorganisms. Front Microbiol, 7, 464.

341 Bisanz, J. E., Enos, M. K., Mwanga, J. R., Changalucha, J., Burton, J. P., Gloor, G. B., et al. (2014).

342 Randomized open-label pilot study of the influence of probiotics and the gut microbiome on toxic

343 metal levels in Tanzanian pregnant women and school children. MBio, 5(5), e01580-01514.

344 Bjorkroth, K. J., Schillinger, U., Geisen, R., Weiss, N., Hoste, B., Holzapfel, W. H., et al. (2002).

345 Taxonomic study of Weissella confusa and description of Weissella cibaria sp. nov., detected in food 346 and clinical samples. Int J Syst Evol Microbiol, 52(Pt 1), 141-148.

347 Collins, M. D., Williams, A. M., \& Wallbanks, S. (1990). The phylogeny of Aerococcus and

348 Pediococcus as determined by 16S rRNA sequence analysis: description of Tetragenococcus gen.

349 nov. . FEMS Microbiol Lett, 70(3), 255-262. 
Damaceno, Q. S., Souza, J. P., Nicoli, J. R., Paula, R. L., Assis, G. B., Figueiredo, H. C., et al.

351 (2017). Evaluation of Potential Probiotics Isolated from Human Milk and Colostrum. Probiotics

352 Antimicrob Proteins, 9(4), 371-379.

353 de Vos, W. M. (2015). Microbial biofilms and the human intestinal microbiome. NPJ Biofilms

354 Microbiomes, $1,15005$.

355 Dressman, J. B., Berardi, R. R., Dermentzoglou, L. C., Russell, T. L., Schmaltz, S. P., Barnett, J. L.,

356 et al. (1990). Upper gastrointestinal (GI) pH in young, healthy men and women. Pharm Res, 7(7),

$357 \quad 756-761$.

358 Dubey, A. P., Rajeshwari, K., Chakravarty, A., \& Famularo, G. (2008). Use of VSL[sharp]3 in the 359 treatment of rotavirus diarrhea in children: preliminary results. J Clin Gastroenterol, 42 Suppl 3 Pt 1, 360 S126-129.

361 Evans, D. F., Pye, G., Bramley, R., Clark, A. G., Dyson, T. J., \& Hardcastle, J. D. (1988).

362 Measurement of gastrointestinal pH profiles in normal ambulant human subjects. Gut, 29(8), 1035-

3631041.

364 FAO/WHO. (2001). Report of the Joint FAO/WHO expert consultation on evaluation of health and

365 nutritional properties of probiotics in food including powder milk with live lactic acid bacteria.

366 Cordoba, Argentina.

367 Fredua-Agyeman, M., \& Gaisford, S. (2015). Comparative survival of commercial probiotic

368 formulations: tests in biorelevant gastric fluids and real-time measurements using microcalorimetry.

369 Benef Microbes, 6(1), 141-151.

370 Garcia, E. F., Luciano, W. A., Xavier, D. E., da Costa, W. C., de Sousa Oliveira, K., Franco, O. L., et

371 al. (2016). Identification of Lactic Acid Bacteria in Fruit Pulp Processing Byproducts and Potential

372 Probiotic Properties of Selected Lactobacillus Strains. Front Microbiol, 7, 1371.

373 Guslandi, M. (2007). Probiotic agents in the treatment of irritable bowel syndrome. J Int Med Res, $37435(5), 583-589$. 
Hsu, Y. M., \& Burnham, C. A. (2014). MALDI-TOF MS identification of anaerobic bacteria: assessment of pre-analytical variables and specimen preparation techniques. Diagn Microbiol Infect Dis, 79(2), 144-148.

Jacobsen, C. N., Rosenfeldt Nielsen, V., Hayford, A. E., Moller, P. L., Michaelsen, K. F.,

Paerregaard, A., et al. (1999). Screening of probiotic activities of forty-seven strains of Lactobacillus spp. by in vitro techniques and evaluation of the colonization ability of five selected strains in humans. Appl Environ Microbiol, 65(11), 4949-4956.

Jafari, S. A., Mehdizadeh-Hakkak, A., Kianifar, H. R., Hebrani, P., Ahanchian, H., \& Abbasnejad, E. controlled trial. Iran J Pediatr, 23(6), 669-674.

Janda, J. M., \& Abbott, S. L. (2007). 16S rRNA gene sequencing for bacterial identification in the diagnostic laboratory: pluses, perils, and pitfalls. J Clin Microbiol, 45(9), 2761-2764. breast milk. Cell Mol Biol (Noisy-le-grand), 63(5), 82-88. lactic acid bacteria. Int J Food Microbiol, 41(2), 103-125.

391 Kraus, M., Cetin, M., \& Aricioglu, F. (2016). The Microbiota and Gut-Brain Axis. JMOOD, 6(3), 172-179.

Levesque, S., Dufresne, P. J., Soualhine, H., Domingo, M. C., Bekal, S., Lefebvre, B., et al. (2015).

394 A Side by Side Comparison of Bruker Biotyper and VITEK MS: Utility of MALDI-TOF MS

395 Technology for Microorganism Identification in a Public Health Reference Laboratory. PLoS One, $396 \quad 10(12), \mathrm{e} 0144878$.

397 Linares, D. M., Ross, P., \& Stanton, C. (2016). Beneficial Microbes: The pharmacy in the gut.

398 Bioengineered, 7(1), 11-20. 
Mandal, H., Jariwala, R., \& Bagchi, T. (2016). Isolation and characterization of lactobacilli from

400 human faeces and indigenous fermented foods for their potential application as probiotics. Can J

401 Microbiol, 62(4), 349-359.

402 Martin, R., Langa, S., Reviriego, C., Jiminez, E., Marin, M. L., Xaus, J., et al. (2003). Human milk is

403 a source of lactic acid bacteria for the infant gut. J Pediatr, 143(6), 754-758.

404 Martinez, R. C., Franceschini, S. A., Patta, M. C., Quintana, S. M., Gomes, B. C., De Martinis, E. C., 405 et al. (2009). Improved cure of bacterial vaginosis with single dose of tinidazole (2 g), Lactobacillus 406 rhamnosus GR-1, and Lactobacillus reuteri RC-14: a randomized, double-blind, placebo-controlled 407 trial. Can J Microbiol, 55(2), 133-138.

408 McCoy, S., \& Gilliland, S. E. (2007). Isolation and characterization of Lactobacillus species having 409 potential for use as probiotic cultures for dogs. J Food Sci, 72(3), M94-97.

410 McElvania TeKippe, E., \& Burnham, C. A. (2014). Evaluation of the Bruker Biotyper and VITEK

411 MS MALDI-TOF MS systems for the identification of unusual and/or difficult-to-identify

412 microorganisms isolated from clinical specimens. Eur J Clin Microbiol Infect Dis, 33(12), 2163-

4132171.

414 Metchnikoff, E. (1908). The microbes of intestinal putrefaction. Comptes Rendus Hebdomadaires

415 Des Seances De L Academie Des Sciences, 147, 579-582.

416 Mignard, S., \& Flandrois, J. P. (2006). 16S rRNA sequencing in routine bacterial identification: a 30417 month experiment. J Microbiol Methods, 67(3), 574-581.

418 Mora, D., Fortina, M. G., Parini, C., \& Manachini, P. L. (1997). Identification of Pediococcus 419 acidilactici and Pediococcus pentosaceus based on 16S rRNA and ldhD gene-targeted multiplex PCR 420 analysis. FEMS Microbiol Lett, 151(2), 231-236.

421 Nduti, N., McMillan, A., Seney, S., Sumarah, M., Njeru, P., Nwaniki, M., et al. (2016). Investigating 422 probiotic yoghurt to reduce an aflatoxiin B1 biomarker among school children in eastern Kenya: 423 Preliminary study. International Dairy Journal, 63, 124-129. 
424 Ocana, V. S., \& Nader-Macias, M. E. (2004). Production of antimicrobial substances by lactic acid

425 bacteria II: screening bacteriocin-producing strains with probiotic purposes and characterization of a

426 Lactobacillus bacteriocin. Methods Mol Biol, 268, 347-353.

427 Owusu-Kwarteng, J., Tano-Debrah, K., Akabanda, F., \& Jespersen, L. (2015). Technological

428 properties and probiotic potential of Lactobacillus fermentum strains isolated from West African

429 fermented millet dough. BMC Microbiol, 15, 261.

430 Ritchie, M. L., \& Romanuk, T. N. (2012). A meta-analysis of probiotic efficacy for gastrointestinal 431 diseases. PLoS One, 7(4), e34938.

432 Salas-Jara, M. J., Ilabaca, A., Vega, M., \& Garcia, A. (2016). Biofilm Forming Lactobacillus: New

433 Challenges for the Development of Probiotics. Microorganisms, 4(3).

434 Sassone-Corsi, M., \& Raffatellu, M. (2015). No vacancy: how beneficial microbes cooperate with

435 immunity to provide colonization resistance to pathogens. J Immunol, 194(9), 4081-4087.

436 Sawada, D., Kawai, T., Nishida, K., Kuwano, Y., Fujiwara, S., \& Rokutan, K. (2017). Daily intake of

437 Lactobacillus gasseri CP2305 improves mental, physical, and sleep quality among Japanese medical 438 students enrolled in a cadaver dissection course. J Funct Foods 31, 188-197.

439 Severance, E. G., Gressitt, K. L., Stallings, C. R., Katsafanas, E., Schweinfurth, L. A., Savage, C. L.

440 G., et al. (2017). Probiotic normalization of Candida albicans in schizophrenia: A randomized,

441 placebo-controlled, longitudinal pilot study. Brain Behav Immun, 62, 41-45.

442 Tamang, J. P., Watanabe, K., \& Holzapfel, W. H. (2016). Review: Diversity of Microorganisms in 443 Global Fermented Foods and Beverages. Front Microbiol, 7, 377.

444 Tharmaraj, N., \& Shah, N. P. (2009). Antimicrobial effects of probiotics against selected pathogenic 445 and spoilage bacteia in cheese-based dips. International Food Research Journal, 16, 261-276.

446 Tirloni, E., Cattaneo, P., Ripamonti, B., Agazzi, A., Bersani, C., \& Stella, S. (2014). In vitro

447 evaluation of Lactobacillus animalis SB310, Lactobacillus paracasei subsp paracasei SB137 and their 448 mixtures as potential bioprotective agents for raw meat. Food Control, 41, 63-68. 
449 Vogenberg, F. R., Isaacson Barash, C., \& Pursel, M. (2010). Personalized medicine: part 1: evolution 450 and development into theranostics. $P$ T, 35(10), 560-576.

451 Westerik, N., Kort, R., Sybesma, W., \& Reid, G. (2018). Lactobacillus rhamnosus Probiotic Food as 452 a Tool for Empowerment Across the Value Chain in Africa. Front Microbiol, 9, 1501.

453 Yano, J. M., Yu, K., Donaldson, G. P., Shastri, G. G., Ann, P., Ma, L., et al. (2015). Indigenous 454 bacteria from the gut microbiota regulate host serotonin biosynthesis. Cell, 161(2), 264-276.

455 Zhang, J. W., Du, P., Gao, J., Yang, B. R., Fang, W. J., \& Ying, C. M. (2012). Preoperative 456 probiotics decrease postoperative infectious complications of colorectal cancer. Am J Med Sci, 457 343(3), 199-205.

458

459 
460 List of figures

461 Figure 1. Photographic (a) and 60x magnification confocal imaging (b) of a 3D nanofibrous scaffold

462 Figure 2. EVOS $^{\circledR}$ FL Imaging of biofilm growth of FSI1-D (A), FSI3-D (B), FSD1-D (C) and FSC3463 LBC (D) at 40x /10x magnification

464 Figure 3. EVOS $^{\circledR}$ FL Imaging of disintegrated 3D scaffold at 40x (C1) and 4x (C2) magnification 465 after growth of FSD1-D

466 
467 List of Tables

468 Table 1. Identification of isolates

469 Table 2. Antimicrobial activity of isolates

470 Table 3. Gastric tolerance of selected isolates

471 Table 4. $0.3 \%$ Bile salt test 